\title{
A study on relationship between organizational culture and organizational commitment
}

\author{
Maryam Khalili*
}

Department of Management and Accounting, North Tehran Branch, Islamic Azad University, Tehran, Iran

\section{H R O N I C L E}

Article history:

Received January 4, 2014

Accepted 1 June 2014

Available online

June 92014

Keywords:

Organizational culture

Organizational commitment

Job involvement

Affective commitment

\section{Introduction}

Organizational commitment plays essential role for the success of economic activities and there are many studies associated with this topic (Kim et al., 2005). Bani et al. (2014), for instance, presented an empirical investigation to learn more about the relationship between employees' psychological empowerment and organizational commitment in revenue agency of city of Semnan, Iran. They reported that there were positive and meaningful relationships between psychological empowerment and organizational commitment components including Sense of efficacy, meaningful, having a choice and trust. However, the survey did not support any relationship between competency and organizational commitment. Chehrazi and Shakib (2014) presented a casual structure model between emotional intelligence and organizational citizenship behavior by applying organizational commitment as mediator variable. They reported that emotional intelligence influenced on organizational citizenship behavior and commitment. The study also reported that organizational commitment affected on organizational citizenship behavior and there were significant relationships between emotional intelligence and its dimensions with organizational citizenship behavior and

\footnotetext{
*Corresponding author.

E-mail addresses: maryamkhalili@yahoo.com (M. Khalili)

C 2014 Growing Science Ltd. All rights reserved.

doi: $10.5267 /$ j.msl.2014.6.018
} 
organizational commitment of employees. Kondratuk et al. (2004) investigated linking career mobility with corporate loyalty. They also investigated how job change could be associated with organizational commitment. Abbasi et al. (2014) investigated the effects of four components of organizational culture on brand promise in one of Iranian producer of detergent and sanitary products. Using Spearman correlation ratio as well as stepwise regression analysis, the study detected that three components of organizational culture including tribal culture, entrepreneurial culture, and market culture influenced positively on brand promise and bureaucratic culture influenced negatively on brand promise.

\section{The proposed study}

This paper presents an empirical investigation to study the relationship between organizational culture and organization commitment. The study uses two questionnaires, one for measuring organizational commitment originally developed by Meyer and Allen (1991) and the other one for organizational culture developed by Denison and Spreitzer (1991). The study is accomplished among selected full time employees who work for an Iranian bank named Bank Saderat Iran. Fig. 1 shows the proposed study of this paper.

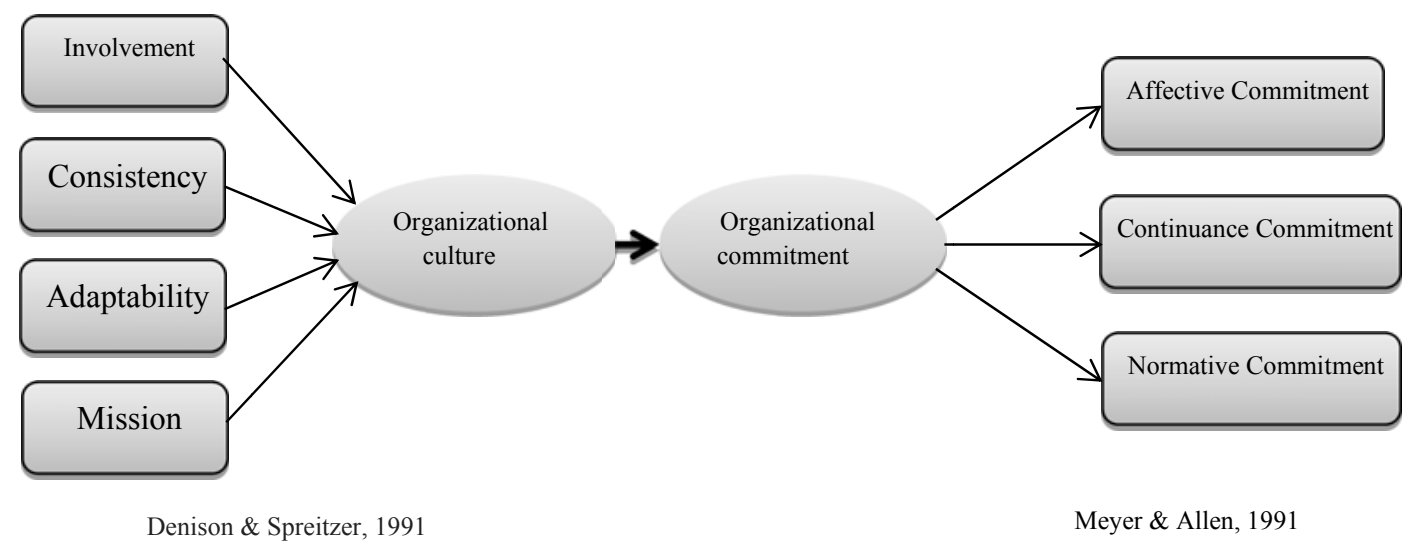

Fig. 1. The proposed study: The effects of organizational culture on organizational commitment

According to Fig. 1, the proposed study of this paper considers the following main hypothesis.

Main hypothesis: There is a relationship between organizational culture and organizational commitment.

In addition, the study considers the following four sub-hypotheses,

1. There is a relationship between job involvement and organizational commitment.

2. There is a relationship between consistency and organizational commitment.

3. There is a relationship between adaptability and organizational commitment.

4. There is a relationship between mission and organizational commitment.

The study is applied among the regular employees who work for an Iranian bank called Bank Saderat Iran. The sample size is calculated as follows, 
$n=\frac{N \times z_{\alpha / 2}^{2} \times p \times q}{\varepsilon^{2} \times(N-1)+z_{\alpha / 2}^{2} \times p \times q}$,

where $N$ is the population size, $p=1-q$ represents the yes/no categories, $z_{\alpha / 2}$ is CDF of normal distribution and finally $\varepsilon$ is the error term. Since we have $p=0.5, z_{\alpha / 2}=1.96$ and $N=1000$, the number of sample size is calculated as $n=210$. Fig. 2 demonstrates personal characteristics of the participants.

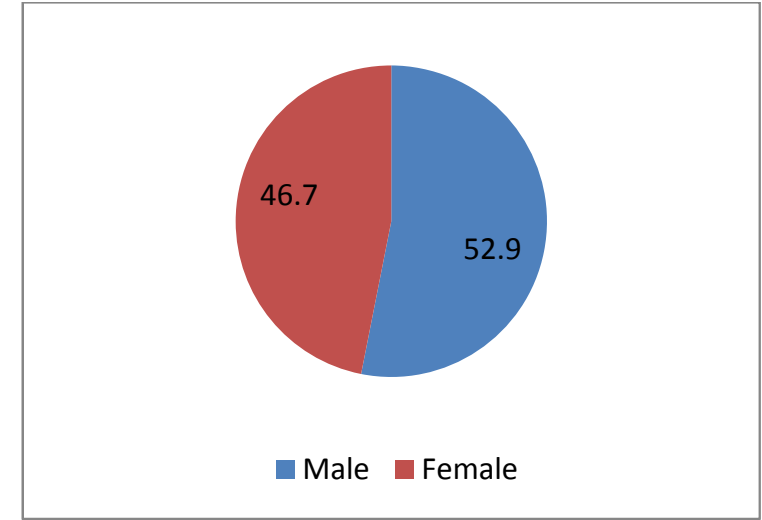

Gender

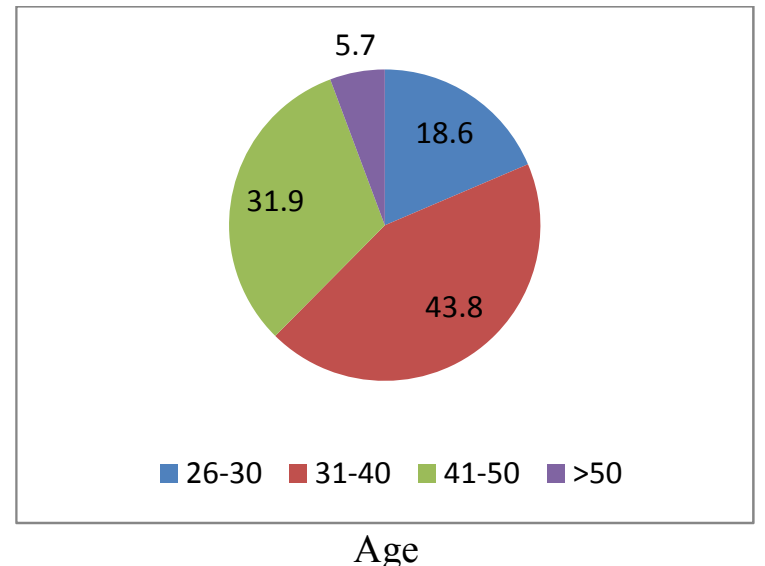

Age

Fig. 2. Personal characteristics of the participants

Based on the results of Fig. 2, most participants in our survey were female middle-aged people. Kolmogorov-Smirnov test indicates that all component of the survey are normally distributed and therefore we use Pearson correlation test to investigate the relationship between different components of the survey.

\section{The results}

In this section, we present details of our findings on testing hypotheses of the survey. Table 1 demonstrates the summary of our findings.

\section{Table 1}

The summary of Pearson correlation test

\begin{tabular}{lccccc}
\hline Variable & Job involvement & Consistency & Adaptability & Mission & Organizational culture \\
\hline Affective commitment & 0.272 & 0.433 & 0.279 & 0.407 & 0.444 \\
Continuance Commitment & 0.101 & 0.258 & 0.237 & 0.341 & 0.292 \\
Normative Commitment & 0.199 & 0.358 & 0.326 & 0.5 & 0.397 \\
Organizational commitment & 0.23 & 0.389 & 0.326 & 0.494 & 0.442 \\
\hline
\end{tabular}

Based on the results of Table 1, there are some positive and meaningful relationship between organizational commitment and organizational culture $(\beta=0.442$, Sig. $=0.001)$. In addition, there are some positive and meaningful relationship between organizational commitment and job involvement $(\beta=0.23$, Sig. $=0.001)$, organizational commitment and consistency $(\beta=0.389$, Sig. $=0.001)$, organizational commitment and adaptability $(\beta=0.326$, Sig. $=0.001)$ and organizational commitment and mission $(\beta=0.494$, Sig. $=0.001)$. In addition, we have applied Freedman test to rank the effects of organizational culture and the results indicate that normative commitment maintains the highest rank $($ Mean $=3.964$ Standard deviation $=0.773)$ followed by Affective commitment $($ Mean = 3.819 Standard deviation $=0.719)$ and Continuance Commitment $($ Mean $=3.677$ Standard deviation $=$ 0.813). We have also performed regression analysis to study the relationship between organizational commitment and organizational culture. Table 2 demonstrates the results of our survey. 
Table 2

The results of regression analysis

\begin{tabular}{cccccc}
\hline \multirow{2}{*}{ Model } & \multicolumn{2}{c}{ Non-standard coefficients } & Standard coefficients & T & Sig \\
& $\beta$ & Standard error & $\beta$ & 7.675 & 0 \\
\hline Intercept & 2.136 & 0.278 & & 2.043 & 0.042 \\
Job involvement & 0.197 & 0.097 & 0.167 & 2.373 & 0.019 \\
Consistency & 0.183 & 0.777 & 0.075 & 1.111 & 0.268 \\
Adaptability & 0.043 & 0.038 & 0.435 & 4.843 & 0.000 \\
\hline Mission & 0.472 & 0.098 & &
\end{tabular}

In Table 2, organizational commitment is dependent variable and the components of organizational culture are independent variables. According to the results of Table 2, three variables including mission, consistency and job involvement influence positively on organizational commitment.

\section{Conclusion}

In this paper, we have presented an empirical investigation to study the relationship between organizational commitment and organizational culture. The study has determined that while there were positive relationships between all components of organizational culture and organizational commitment, mission and consistency affected organizational very strongly. The results of our survey are consistent with other studies on the literature (Bani et al. 2014; Abbasi et al., 2014; Chehrazi \& Shakib, 2014).

\section{Acknowledgement}

The authors would like to thank the anonymous referees for constructive comments on earlier version of this paper.

\section{References}

Abbasi, H., Abbasi, H., Faraji, A \& Hajirasouliha, M. (2014). Investigating the effects of organizational culture on brand promise. Management Science Letters , 4(5), 1039-1042.

Bani, M., Yasoureini, M \& Mesgarpour, A. (2014). A study on relationship between employees' psychological empowerment and organizational commitment. Management Science Letters, 4(6), 1197-1200.

Chehrazi, S \& Shakib, M. (2014). A study on the relationship between emotional intelligence, organizational commitment and organizational citizenship behavior. Management Science Letters , 4(6), 1103-1106.

Denison, D. R., \& Spreitzer, G. M. (1991). Organizational culture and organizational development: A competing values approach. Research in organizational change and development, 5(1), 1-21.

Kim, W. G., Leong, J. K., \& Lee, Y. K. (2005). Effect of service orientation on job satisfaction, organizational commitment, and intention of leaving in a casual dining chain restaurant. International Journal of Hospitality Management, 24(2), 171-193.

Kondratuk, T. B., Hausdorf, P. A., Korabik, K., \& Rosin, H. M. (2004). Linking career mobility with corporate loyalty: how does job change relate to organizational commitment?. Journal of Vocational Behavior, 65(2), 332-349.

Meyer, J. P., \& Allen, N. J. (1991). A three-component conceptualization of organizational commitment. Human resource management review, 1(1), 61-89. 